\title{
Economic analysis on application of exhaust air heat recovery in existing public buildings in the severe cold regions
}

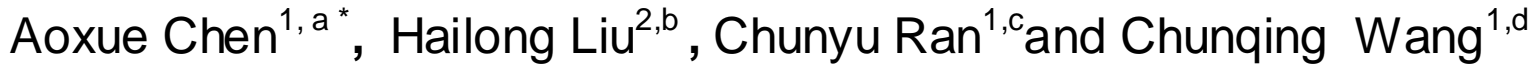 \\ ${ }^{1}$ chool of Municipal \& Environmental Engineering,Jilin Jianzhu University,Changchun, P.R.China \\ ${ }^{2}$ Fourth Design Institute,Jilin Provincial Architectural Design Institute Co.,Ltd,Changchun, P.R.China

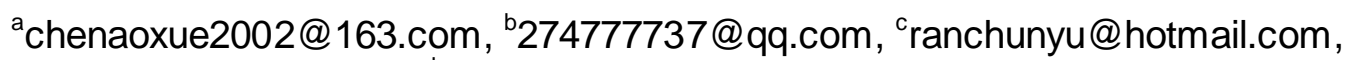 \\ dwangchunqing@hotmail.com
}

Keywords: the severe cold region; heat recovery from exhaust air; rotary wheel exchanger; plate-fin heat exchanger; public buildings; the recovery fresh air heat pump units; economic analysis.

Abstract. Characteristics of different heat recovery devices from exhaust air were introduced.An actual project was taken as an example,three heat recovery systems from exhaust air by rotary wheel exchanger,plate- fin heat exchanger and recovery fresh air heat pump units were presented. The energy saving and economic of these heat recovery systems were analyzed.Initial investment and payback period of the system was reckoned.Considering the above situation, the recovery fresh air heat pump unit has a considerable energy saving potential.

\section{Introduction}

According to the promotion of the national energy saving and emission reduction policies, and taking the climate features of the severe cold regions into consideration, heat recovery system has attracted more and more attention as an effective measure for energy-saving and emission reduction. There are several characteristics about exhaust air of buildings, the amount of exhaust air is larger, it has strong recovery.Emission is relatively concentrated, it can reuse through some kind of wind system and water system. The running time of heat recovery devices from exhaust air is too long, waste heat of exhaust air is relatively stable in a long time.For the recycling of construction waste heat reuse, first of all, find the nearest place and application which need for extensive low grade thermal energy. Secondly, the grade of the heat energy and waste heat should be the same. The time which waste heat generated and needed synchronized as possible, or cyclical changes. So the construction waste heat is more and more recyclable.

\section{Characteristics of diffe rent heat recovery devices from exhaust air}

There are several different heat recovery devices from exhaust air,such as rotary wheel exchanger,plate- fin heat exchanger, heat pipe type exchanger,intermediate media type exchanger and heat pump heat recovery forms.Heat pipe type, intermediate media type exchanger are sensible heat exchanger, heat recovery ventilation device with sensible heat exchanger only recover sensible heat, these devices are very suitable for severe cold regions. The heat exchanger of the rotary wheel, the plate fin and the heat pump can not only recover the sensible heat in the humid air, but also can recover the latent heat in the wet air. The full thermal recovery ventilation device is suitable for the hot and cold regions,and can effectively avoid the problem of the condensation water.Various heat exchanger has its own characteristics, the different forms of heat exchanger performance, efficiency and utilization, equipment costs, the difficulty of maintenance are not identical.

Considering the aspect of heat recovery efficiency, the energy recovery device is prior to rotary wheel heat exchanger and plate fin heat exchanger.But it has the disadvantages, such as large volume, high initial investment, high maintenance cost, long payback time of investment, etc., and it is not very economical.From the view of energy saving and economic point, the operation and maintenance costs,payback time of investment of heat pipe heat exchanger and so on are better than rotary wheel exchanger,but the initial investment is high,can only recover the sensible heat. 
In severe cold regions, considering the frost resistance of heat exchanger,although rotary wheel heat exchanger has self-cleaning function, the speed is controlled,it adapts different parameters of indoor and outdoor air, heat recovery efficiency is high,but rotary wheel heat exchanger is two medium exchange conversion, it can not completely avoid the cross contamination, gas which flows devices must be not harmful substances, and equipment occupies large space, the flexibility of taking over is poor, it has belt transmission device, and consumes a certain amount of kinetic energy consumption, frost resistance ability is poor, it not suitable for heat recovery device of the severe cold area in winter. Plate fin heat exchanger has several advantages,such as simple structure, safe and reliable operation, no transmission equipment, the cost of equipment is low, but the plate fin heat exchanger only can transfer surface heat exchange through the wall, when the surface temperature is lower than the dew point of the cooled air, it generated condensation water.If the quantity of condensation water is large, it will block up the channel. If the air temperature is lower than 0 degree, it will frost, channel congestion is more serious.Such as equipment which recover exhaust heat in winter should not be used in northern severe cold regions. Heat pipe heat exchanger without power consumption, it transfer heating with another medium phase change, but relative to the efficiency of rotating wheel heat exchanger and plate fin heat exchanger,the efficiency of heat pipe exchanger is lower[1-3].

Heat pump exchanger has several advantages,such as high efficiency, flexibility, long life and other advantages, but it occupies large space, at the beginning of the equipment investment and maintenance costs is expensive, the frost resistance is not strong. Therefore, the heat recovery type heat exchanger is improved, it applies heat recovery exchanger to exhaust heat recovery system, the system recover exhaust air heating to preheat the outdoor air. Only in this way can solve the heat pump antifreeze problems.

\section{Design scheme of exhaust heat recovery system}

General situation of the project. The project was located in Jian city of Jilin Province and a production of training center, the project has three floor on the ground, construction area is 6576 square meters. The air conditioning system of production training center was designed for cooling in summer and heating in winter. The calculation of outdoor air temperature of air conditioning in winter is - 26 degree, the calculation of indoor air temperature of air conditioning in winter is 18 degree. The project supplies indoor air using the fresh air unit and fan coil together, the fresh air unit provides fresh air to indoor, it ensured the indoor air quality.Considering the air units often break in winter, in order to the system can work in winter, it must heat the fresh air,so the new scheme uses the exhaust heat recovery system to preheating outdoor air.

Design scheme of the exhaust heat recovery system in existing public buildings. The project was designed which adopt heat recovery system as an example,taking into account that transfer equipment, heat recovery efficiency and applicability of the severe cold re gions, and economy of existing building renovation, it designed three kinds of exhaust air heat recovery scheme.In scheme 1, a rotary heat exchanger was adopted, which recover exhaust air heat.In scheme 2, the plate fin heat exchanger recovered exhaust air heat, and in scheme 3 , the system used heat pump recovery system to recover heat.On the basis of the original fresh air system, the heating was recovered which used these schemes, and analyzed the economic.

The heat recovery scheme 1 and 2 respectively used the rotary heat exchanger and plate fin heat exchanger which recover exhaust heat. Using the two kinds of methods for exhaust heat recovery, only need to add the exhaust pipeline in the original system. Heat recovery scheme 3 is composed of air conditioning unit and heat pump unit- recovery fresh air heat pump units to recover exhaust air heat. The system added wind pipes and heat pump unit in the original fresh air system, the original air system did not change, only cold / hot water pipe of fresh air machine in fresh air system and supply and return water pipe of air conditioning system is connected.In the heat recovery scheme, recovery fresh air heat pump units are the evaporator (condenser) of the heat pump units instead of the air heater (cooler), which the heating (cooler) medium is water in fresh air conditioning unit.Fresh air unit processed energy consumption of fresh air which required no longer taken by fresh air unit all 
responsibilities, but recovered by the heat pump system discharge exhaust heat to preheat fresh air, reduced the load of fresh air, the rest is undertook by air conditioning units.

\section{Economic analysis of exhaust air heat recovery in existing public buildings in the severe cold regions}

Due to the application of the exhaust heat recovery system to bear the heating load of the part of the fresh air system,the total heating load of air conditioning system is reduced. The total thermal efficiency of the rotary wheel heat exchanger was $80 \%$ in the heat recovery scheme 1 . The heat recovery efficiency of the plate fin heat exchanger was $70 \%$ in heat recovery scheme 2 .In heat recovery scheme 3 , the heat recovery efficiency of the recovery fresh air heat pump units, which according to the experimental test, changed between the $72 \%$ 87\%, the average of heat recovery efficiency up to $78 \%$, fresh air preheating temperature can reach more than 10 degree. Put the three kinds of exhaust heat recovery system into practical engineering, compared the energy saving and economy of these three ways.

This project used three kinds of heat recovery plan separately, the coal saving amount of the three kind of schemes, and the heating operation saving expense was calculated, and translated into the electric quantity. According to the survey, coal prices have been rising, comprehensive coal at 850 yuan per tons of standard coal, without considering the situation, the system reduces coal transportation, savings, labor cost and environment governance cost in the case of save coal consumption, the annual saving costs of heating operation is calculated.There are two kinds of calculation methods of electric calorific value, one calculation is based on the theory of calorific value, Another calculation is based on power consumption. The theory of calorific value is calculated according to every degrees of power containing the mechanical equivalent of $860 \mathrm{kcal}$ heating, it means containing standard coal about $0.1229 \mathrm{~kg}$. Calculated with the power consumption, every year is different, in order to compare, the National Bureau of statistics make a standard of each electric equivalent to standard coal about $0.404 \mathrm{~kg}$, as a future power conversion of standard coal coefficient[4]. Compared energy conversation and economical to two systems. It is shown in table 1.

Table 1 Compared energy conversation and economical of system

\begin{tabular}{|c|c|c|c|c|c|c|}
\hline & $\begin{array}{c}\text { Fresh } \\
\text { air heat } \\
\text { load } \\
(\mathrm{KW})\end{array}$ & $\begin{array}{l}\text { Saving quantity of } \\
\text { standard coal every } \\
\text { day (unit: } \mathrm{kg} \text { ) }\end{array}$ & $\begin{array}{c}\text { Saving quantity } \\
\text { of standard } \\
\text { coal every } \\
\text { year(unit: } \mathrm{t} \text { ) }\end{array}$ & $\begin{array}{l}\text { Saving costs of } \\
\text { heating operation } \\
\text { every year (unit: } \\
\text { million yuan) }\end{array}$ & $\begin{array}{c}\text { Power } \\
\text { consumption } \\
\text { (unit: } \\
\text { million } \mathrm{kWh} \text { ) }\end{array}$ & $\begin{array}{c}\text { Electric charge } \\
\text { (unit: million } \\
\text { yuan) }\end{array}$ \\
\hline $\begin{array}{l}\text { original } \\
\text { design of } \\
\text { engineeri } \\
n g\end{array}$ & 154.1 & -245.42 & -41.09 & -3.49 & 10.18 & 5.35 \\
\hline scheme 1 & 123.3 & 197.56 & 32.99 & 2.81 & 8.17 & 4.29 \\
\hline scheme2 & 107.9 & 172.34 & 28.78 & 2.45 & 7.13 & 3.74 \\
\hline scheme 3 & 127.3 & 201.62 & 33.74 & 2.86 & 8.36 & 4.39 \\
\hline
\end{tabular}

As shown in table 1, the scheme of exhaust air heat recovery was economic than original design in aspect of the heating load of fresh air, saving quantity of standard coal, saving costs of heating operation, power consumption and electric charge. Using the original design scheme, the system need heating load for fresh air is $154.1 \mathrm{~kW}$. Using heat recovery scheme 1 from exhaust air can recover the heating up to $123.3 \mathrm{~kW}$, scheme 2 was $107.9 \mathrm{~kW}$, scheme 3 was $127.3 \mathrm{~kW}$.The daily standard coal consumption was $245.42 \mathrm{~kg}$, if using the original design scheme, each year will need 41.09 tons of standard coal consumption, but the using the new design scheme, saving quantity of standard coal respectively was $197.56 \mathrm{~kg}, 172.34 \mathrm{~kg}, 201.62 \mathrm{~kg}$ every day, the building annual coal consumption can be decreased respectively $32.99,28.78$ and 33.74 tons of standard coal, electricity can be saved about 8.17 million $\mathrm{kWh}, 7.13$ million $\mathrm{kWh}, 8.36$ million $\mathrm{kWh}$, saving electricity fee was 4.29 million yuan, 374 million yuan, 4.39 million yuan. Therefore, using the heat recovery scheme from exhaust air is a tremendous energy saving potential of energy consumption for heating system, which scheme 3 of the energy-saving effect is more obvious. 


\section{Conclusion}

Characteristics of different heat recovery devices from exhaust air were compared,taking the climate features of the severe cold regions into consideration, an actual project was taken as an example,three kinds of exhaust air heat recovery scheme were selected, compared and analyzed the energy saving and economic.

Through analyzed heat recovery system from exhaust air, it is concluded that: considering the heat recovery efficiency, relative to sensible heat exchanger, such as the heat pipe, the heat recovery efficiency of total heat exchanger is higher than sensible heat transfer, but total heat exchanger equipment has several disadvantages,such as high cost, occupied space greatly, and plate fin heat exchanger existed cross contamination. Take frost resistance of heat exchanger into consideration, heat recovery efficiency of rotary heat exchanger is higher, but its frost resistance ability is poor. When the fresh air temperature below 0 degree, plate fin heat exchanger will frost; heat recovery efficiency of heat pipe exchanger is low.

This project used three kinds of heat recovery plan separately, the coal saving amount of the three kind of schemes, and the heating operation saving expense was calculated, and translated into the electric quantity, from the analysis results show that the scheme 3 of the energy-saving effect is most effective. Regardless of the advantages and disadvantages of various devices, from the perspective of energy saving,they all can be used. But the choice of heat recovery device, combined with the several factors,such as actual situation of the local climatic conditions, economic conditions, engineering, harmful gases from exhaust air, taken the technical and economic analysis into account to determine the suitable selection of heat recovery device, so as to achieve spending less investment, recycle more heating.

\section{Acknowledgment}

The project also has been supported by science and technology research projects of the Education Department of Jilin Province.Research on the recovery fresh air heat pump units in the air conditioning energy saving reform of existing public building in the serious cold regions, thanks to technology and financial support of Education Department of Jilin Province.

The project has been supported by science and technology development project funding for ministry of housing and urban-rural development of the people/s republic of China. The manufacture of recovery fresh air heat pump unit suitable for severe regions. project Numbers: NO. 2010-k1-45, thanks to technology and financial support of ministry of housing and urban-rural development of the people/s republic of China.

\section{References}

[1] Qiang An,Xiaojun Gao,Economic Analysis on Application of Exhaust Air Heat Recovery in Hot Air Heating System,Proceedings of the Journal of Architecture Technology [J], Beijing, vol.44, pp.1090-1092, 2013.

[2] Xinhua Wang,Yingting Peng,Zehua Liu,Yang Nie,Industrial Building Exhaust Heat Recovery Plan Research,Proceedings of the Contamination Control\&Air-conditioning Technology[J], Beijing, vol.6, pp.8-11, 2013.

[3] Haoran Xie,Application of Energy Efficiency Technique in a Super Hing-rise Building Air Condition Design,Proceedings of the Power Generation and Air Condition[J], Beijing, vol.34, pp.81-85, 2013.

[4] LiguoFang, Technology Application and Valuation Skills, Proceedings of the Chemical Industry Press[M], Beijing, pp. 31-38, 2008. 